\title{
Research on Teaching Methods about Training Dance-major Students' Artistic Expressive Force
}

\author{
Chao Qu \\ Taishan University, Tai'an, 271000, China
}

Keywords: Dance major, Artistic expressive force, Teaching methods

\begin{abstract}
The dance is a kind of artistic form with great artistic appeal; it generally delivers its artistic expressive force to the audience through dancers and then bring the corresponding aesthetic pleasure to the audience. This paper combines with factors which influence students' artistic expressive force in dance teaching to carry out the corresponding research on teaching methods about training students' artistic expressive force in dance for the hope of practically improving teaching quality and laying a firm foundation for students' future development.
\end{abstract}

\section{Introduction}

The artistic expressive force is the external infection shown by relevant artistic work in the exhibition, and different type of artistic work can deliver their internal artistic thoughts to appreciator through external artistic form, such as the meaning, spiritual demand, and creative emotion that one artistic work wants to express. As the artistic form with great expressive force and infection in art, the dance is direct and instant in terms of artistic infection, which determines that the dance performer must show high-level artistic expressive form in the dance performance to certain degree; the dancers make use of their thinking to perform and deliver the ideological content of one work and make the work truly show its artistic vitality. Meanwhile, under the influence of education reform in China, the dance-major teaching continuously innovates and improves its teaching system for the hope of improving students' professional quality via more scientific teaching method. However, the research practice shows that the pure expansion of teaching width and deepening of teaching depth can't cause direct influence on students' artistic expressive force in the process of their dance performance. Therefore, the dance education major shall start from the internal and external factors which influence students' artistic expressive force in dance performance, and then combine with influence factors to carry out more professional teaching so as to gradually improve students’ artistic expressive force.

\section{Factors influencing dance-major students’ artistic expressive force}

\section{Internal factors}

The internal factors which can cause influence on dance-major students' artistic expressive force mainly include students' artistic culture, knowledge reserve, and humanistic quality. In terms of artistic culture, students' artistic culture is generally expressed from thoughts and emotions as well as knowledge and art, all of which determine the level of students' dance performance. As for dance-major students, the knowledge reserve not only refers to students' reserve of theoretical knowledge, but also refers to students' reserve of information about dance-major technical movement; furthermore, the students have fully digested relevant technology and then easily and freely show the technology in dance performance. The humanistic quality specifically refers to a kind of interior quality formed by knowledge system, ideology, personal ability, will, emotion, and other relevant factors, and it can show personal temperament and culture. ${ }^{[1]}$ If a student has high humanistic quality, he or she must have high ability of comprehending the knowledge, and be able to deeply understand and master various basic elements in learning dance technology, digest relevant knowledge points in the actual performance process, and then show corresponding artistic aesthetics and performance value. In the practice training of dance-major teaching, the teachers shall pay great attention to the internal factors which can cause influence on students' artistic expressive force so as to let students 
gradually form the self artistic appreciation ability and artistic infection and then lay a good foundation for the formation of artistic expressive force.

\section{External factors}

There are also many external factors which can cause influence on training students' artistic expressive force, such as dance-major teachers' classroom teaching training, internal relation between performed music rhythm and related movement, artistic expression of arrangement of dance movement, and external expression of relevant body language. In the dance-major teaching practice, the artistic quality-oriented education implemented by teachers on students in classroom teaching play certain guiding role in students' growth; therefore, in the teaching practice, the teachers must ensure that they have high artistic accomplishment in dance; while they teach dance movement, they can infect students' emotion and stimulate students' learning interest through limbs, body, and language art, and even cause active influence on students' improving their comprehension ability and construct the practical teaching context with great artistic infection for students ${ }^{[2]}$. In the teaching, the teachers shall be also clear that the music rhythm is the soul of dance performance, and the exhibition of relevant movement needs the guidance and support of soul. Therefore, a set of good dance movement not only shall have beauty of expressive form, but also have the corresponding beauty of music rhythm so that the students can improve artistic expressive form of dance performance through mastering the internal relation between music and dance. Meanwhile, the reasonable arrangement of dance movement can also stimulate students' artistic expressive ability. In the teaching practice, the teachers can let students carry out suitable adjustment on dance arrangement through their understanding on dance work to enhance the artistic infection of dance and make the students' dance performance bring people a kind of unique aesthetics. It can be said that the external factors cause a decisive influence on students' artistic expressive force. In the teaching practice, the teachers shall pay attention to the influence of external factors on students, and improve students' artistic expressive force through suitably enhancing the teaching proportion of external factors.

\section{Teaching methods about training dance-major students' artistic expressive force}

As the key for a dancer to express the spirit of a dance work, the artistic expressive force stands for artistic value and vitality of dance performance to certain degree. In the practice of dance teaching, the following methods shall be adopted in order to train students' artistic expressive force:

\section{Teaching methods about training dance-major students’ external movement form}

\section{To enhance basic skills training in teaching practice}

The dance-major basic skills training is a basic part of dance teaching. Due to the fact that the dance performance has a high requirement for performer's flexibility at each part of body and requires the performer to master high artistic skills, and all of those can be obtained via long-time learning of basic skills, it is required to increase the proportion of basic skills training in overall teaching in the dance teaching, respectively set flexibility training and skills training so that the students can understand the optimal combination between dance movement and emotion of work while they lay a good dance foundation, for example, the movements with large movement range and strong strength are generally used to show the feeling of anger in the work; in this way, it is able to enhance students' artistic expressive force in dance performance.

To introduce folk dance in the teaching practice to enhance the figurativeness of students' dance performance

In the dance language art, the dance performer can show high-quality dance work to the audience and deliver true emotion to the external world only after they can ensure clear and fluent movement. Therefore, to train students' body movement ability in the teaching is of important realistic significance. Due to rich form of performance, Chinese traditional folk dance also has various kinds of movement skills, and the relevant movement combination is full of rich emotion. Therefore, to introduce the folk-dance combined movement teaching in the dance-major teaching not only can make teaching content become more diversified and richer, but also can let students enhance the 
ability to express their dance emotion unconsciously. Therefore, in the teaching process, the teachers shall combine professional dance teaching with folk dance teaching, and make use of colorful dance language and skill training to effectively improve students' way of dance expression and enhance the effect of classroom teaching.

\section{To rehearse dance programs with strong artistic expressive force on a regular basis}

At current stage, most of dance major in China have low entrance threshold. Some of dance-major students only have accepted easy dance teaching training before entering into dance major; although it is good for popularization of Chinese dance education in the society, it is not good for professional development of dance education. Therefore, in the dance-major teaching practice, the teachers shall pay equal attention to the development of students at different stage, and suitably arrange some basic dance with low difficulty but rich emotion contained in daily teaching so that each student can participate into teaching performance and the students' learning enthusiasm can be enhanced ${ }^{[4]}$. Meanwhile, through regular emotional education and learning and performance of artistic expression, it is able to let students deepen their understanding on emotion of various kinds of dance works and improve the ability to control the emotion of their dance performance so as to create condition for improving their artistic expressive force.

\section{Teaching methods about inner feeling education}

To implement experience teaching of inner feeling education

The feeling is the most favorable tool which moves people. In order to make the dance move people, the dance performers shall firstly guarantee that the dance they perform can move themselves; only after a spiritual resonance between dancer and dance happens, that is, the dancer's expression and movement agree with the emotion which the dance shall express, it is able to truly cause the audience's resonance and obtain the audience's acceptance. In the specific teaching practice, the teachers shall adopt certain measures to improve students' ability of understanding and controlling the relevant dance works. In the classroom teaching, except for explaining relevant movement skills to students, the teachers shall place dance works or corresponding classic movements into cultural background to let students truly understand creators' creative intention through creative background and then improve the ability of controlling the dance. Take the teaching practice of folk dance as an example: before the teachers impart the performance and skills of folk dance to the students, they shall introduce the sprouting, production, and development of relevant type of dance, place of origin, and local conditions and social customs, creator's growth process, artistic tendency and dance style etc. to the students so that the students can deeply understand the thoughts and emotions that the dance shall deliver, improve their inner appreciative ability, and then improve their artistic expressive force in dance after they fully know the dance background.

To implement suitable training for students' rhythm of inner feeling

While the corresponding fluctuation happens in personal inner feeling, the change will happen in individual's external physical state accordingly. Therefore, through consciously controlling the rhythm of inner feeling, and driving the change in body movement and posture via regular change in rhythm, it is able to make dancer's dancing posture full of rich emotion. Therefore, in the dance-major teaching, the teachers shall consciously guide students to control the rhythm of inner feeling and carry out frequent training to enhance the feeling of students' dance performance ${ }^{[5]}$. In the specific operation, the teachers can suitably introduce different type of music appreciation teaching in the teaching practice to let the students improve their sensitiveness to music and understanding of expression of music feelings through music appreciation teaching, and then combine with culture and art education to open students' vision, suitably improve students' ability of understanding artistic emotion and personal cultural details to create a condition for students to enhance their ability of controlling the rhythm of inner feelings.

To improve students' thinking and creative ability via modern dance education and arrangement education

In the dance education system, compared to other dance education, the modern dance education pays more attention to training students' thinking and creative ability, thus there is certain difference 
between modern dance and Chinese traditional folk dance. Each modern dance work generally has a relatively complete story background, and strong layer and three-dimension degree of figure expression, which creates a new dance field about explaining people's inner feelings. In the modern dance teaching, except for guiding students to learn single dance movement, the teachers shall also suitably increase and arrange education content according to property and feature of modern dance, encourage students to reasonably utilize dance language to tell their stories, and deliver their inner feeling. In this way, in the teaching, due to the fact that the students can personally participate in dance creation and even final performance process, they can improve their ability of understanding dance programs, which then lays a foundation for further enhancing students' artistic expressive force in dance.

\section{Considerations in training students' artistic expressive force in dance teaching}

Firstly, the training of basic skills teaching shall be scientific. The training of basic skills training is the basis to train students' expressive force in dance and it plays an extremely important role in the practice of dance teaching. However, in the dance-major teaching, instead of merely enhancing basic skills training, the teachers shall follow certain scientific rules; when a repeated operation is needed on one training, the teachers shall urge students to realize the practice times and ensure training effect. however, when the training content is relatively easy, the teacher shall avoid repeated teaching on this movement to avoid the situation that the high-strength basic skills training cause the stiffness in students' muscle and the overall learning effect is influenced. As is known to use, the dance training and performance process have high demand for performer's body movement, and the performer shall be able to fully stretch their body and ensure consistent movements; however, the muscle stiffness brought by high-strength training will not only let students unable to show the aesthetic feeling of dance in dance movement, but also influence teaching practice at next stage, which is not good for training students' artistic expressive force. Therefore, the dance teachers shall arrange the course in a scientific way according to objective rules to ensure good control and improve teaching effect.

Secondly, the dance teaching shall pay attention to organic combination of theory and practice. Through learning the theory of dance art, it is able to enhance students' inherent temperament, and the practical teaching can improve students' external infection in dance performance; through combination of theory and practice, it is able to cultivate students' artistic expressive force in essence. Therefore, while insisting on classroom theory teaching, the teachers shall create the opportunity of social practical learning for students; on the basis of improving students' performance skills, it is able to also stimulate students' enthusiasm in dance learning through performance and enhance students' ability to control the artistic expressive force of dance.

\section{Conclusion}

The training of artistic expressive force in dance is an important part of dance-major teaching, and the dance teachers shall pay high attention. Therefore, in the teaching practice, the teachers shall cultivate students' artistic expressive ability from many perspectives according to students' phased growth features so as to show the soul and life of dance art.

\section{References}

[1] Wang Zhao: Discussion on Factors Influencing Artistic Expressive Force in Dance, Public Art, 2014 (3): 158-159.

[2] Wu Bo: Training Students’ Artistic Expressive Force in Dance, Northern Literature, 2013 (11): 125-126.

[3] Zhou Wenying, Wang Shunxi, He Lingjie, et al.: Analysis on Main Factors Influencing Artistic Expressive Force of Sports Dance and Countermeasures, Contemporary Sports Technology, 2014 (34): 247-248. 
[4] Li Xiaoqin: Discussion on Training Strategies about Students' Artistic Expressive Force in Middle School Dance Teaching, Examination Weekly, 2014 (59): 165-165.

[5] Wang Yanmei: Cultural Exploration on Artistic Expressive Force of Sports Dance, Intelligence, 2014 (9): 273-273. 